\title{
Genitourinary Considerations in Reoperative and Complex Colorectal Surgery
}

\author{
Azah A. Althumairi, $\mathrm{MD}^{1}$ Jonathan E. Efron, $\mathrm{MD}^{1}$ \\ ${ }^{1}$ Department of Surgery, Johns Hopkins University School of Medicine, \\ Baltimore, Maryland \\ Clin Colon Rectal Surg 2016;29:145-151.

\begin{abstract}
Address for correspondence Jonathan E.Efron, MD, Department of Surgery, Johns Hopkins University School of Medicine, Blalock 618, 600 N Wolfe Street, Baltimore, MD 21287

(e-mail: jefron1@jhmi.edu).
\end{abstract}

\begin{abstract}
Keywords

- complex colorectal surgery

- genitourinary injury

- ureter

- bladder

- urethra

Genitourinary structures are at risk of injury during colorectal surgery. The incidence of injury is low; however, the risk is higher in cases involving severe inflammatory or infectious processes, locally advanced or recurrent cancer, previous radiation, and reoperation. Consideration of the anatomical relationship between the genitourinary system, and the colon and rectum is crucial to avoid injuries. Intraoperative diagnostic techniques such as intravenous pyelogram (IVP), fluoroscopic cystogram, or retrograde urethrogram can aid in identifying suspected injuries. Early recognition and repair of injuries decrease the morbidity of an injury. Repair of injuries depends on the location and extent of the injury. Simple injuries may be repaired primarily, while complex injuries may require more advanced repairs such as a flap reconstruction.
\end{abstract}

Genitourinary structures are susceptible to iatrogenic injury during colorectal surgery due to their anatomical proximity to the colon and rectum. The most commonly injured organ is the ureter, followed by the bladder and the urethra. ${ }^{1}$ The risk of injury increases with the increasing complexity of the operation. Factors that increase the complexity of a colorectal operation are a severe inflammatory process such as diverticulitis or inflammatory bowel disease (IBD), a severe infection with pelvic or lateral pelvic side wall abscesses, locally advanced or recurrent cancer that distorts normal surgical planes, previous radiation, and a reoperative field. ${ }^{2,3}$ The risk of injury can also depend on the surgeon's experience, especially with minimally invasive approaches. Understanding risk factors, mechanisms of injury, and techniques for injury prevention is crucial as such injuries can result in a significant short- and long-term morbidity. We will discuss the genitourinary structures that are at risk of injury during colorectal surgery, the techniques for injury prevention, and the management options in cases of inadvertent injuries.

\section{Ureter}

Due to the anatomic relationship between the left ureter and the left-sided colon mesentery, ureteral injuries associated with colorectal surgery occur most frequently during abdom- inoperineal resection (APR), low anterior resection (LAR), or sigmoid resection. ${ }^{4-7}$ The left ureter is adjacent to the descending and sigmoid colon and is crossed ventrally by inferior mesenteric artery and its branches. The right ureter is adjacent to the cecum and is crossed ventrally by the right colic and ileocolic vessels. Injuries usually occur at the takeoff of the inferior mesenteric artery, at the pelvic brim where the ureter is crossed by the infundibulopelvic ligament with the uterine vessels, and in the pelvis as they enter the bladder (-Fig. 1). These injuries may consist of laceration, ligation, devascularization, or a thermal injury from an energy device. ${ }^{1}$

The reported incidence of ureteral injuries is low, and the risk of injury is influenced by multiple factors including the primary surgical indication, the type of surgery and its degree of complexity, an open or minimally invasive surgery (MIS) approach, and the surgeon's experience. A retrospective population-based study in the Unites States including over 2.1 million colon and rectal operations reported an incidence of ureteral injury of $0.28 \%$ (6,027 cases). ${ }^{8}$ Risk factors associated with ureteral injury included cancer with nodal involvement or distant metastatic disease, history of weight loss and malnutrition, and chronic steroid use. Rates of ureteral injury were higher at teaching hospitals compared with nonteaching hospitals (3.4/1,000 vs. $2.3 / 1,000 ; p<0.001)$. Rectal cancer was associated with the highest rates of $(7.1 / 1,000)$, followed
Issue Theme Complex and Reoperative Colorectal Surgery; Guest Editor: Cindy Kin, MD, MS, FACS
Copyright $\odot 2016$ by Thieme Medical Publishers, Inc., 333 Seventh Avenue, New York, NY 10001, USA. Tel: +1(212) 584-4662.
DOI http://dx.doi.org/ $10.1055 / \mathrm{s}-0036-1580629$. ISSN 1531-0043. 


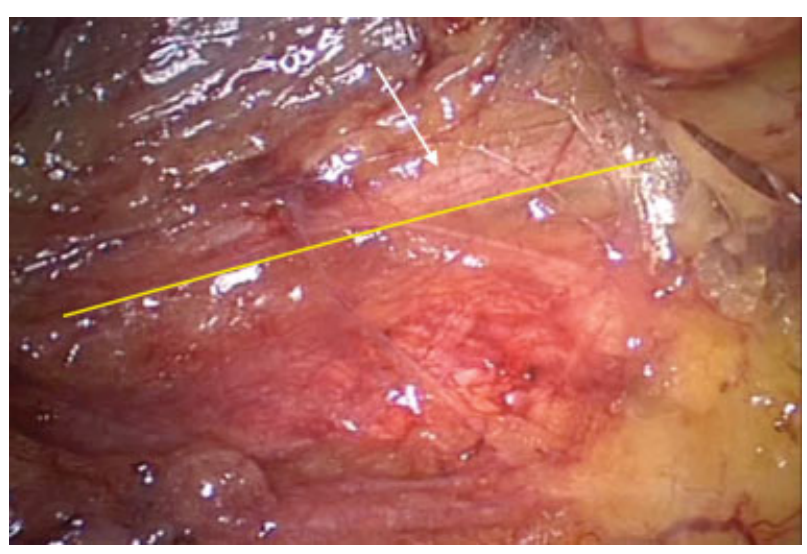

Fig. 1 Left ureter courses in the retroperitoneum (arrow identifies ureter with the line depicting the course).

by diverticular disease and Crohn disease (2.9/1,000 for both). Laparoscopic surgery was associated with lower rates of ureteral injury $(1.1 / 1,000)$ compared with open surgery $(2.8 / 1,000)$. This is likely a reflection of the higher complexity of cases done in an open fashion, as conversion from laparoscopic to open approach was associated with the highest rates of ureteral injury $(7.9 / 1,000)$. APR was associated with the highest rates of ureteral injury $(7.6 / 1,000)$, followed by anterior resection $(5.8 / 1,000)$. Multivariate analysis demonstrated that the predictors of ureteral injury were rectal cancer (odds ratio [OR]: 1.85), presence of adhesions (OR: 1.83 ), lymph nodes or distant metastatic cancer (OR: 1.76), weight loss (OR: 1.08), and surgery performed at teaching hospital (OR: 1.05). Protective variables were laparoscopic surgery (OR: 0.91), transverse colectomy (OR: 0.90 ), and right colectomy (OR: 0.43). ${ }^{8}$ Data from the National Surgical Quality Improvement Program (NSQIP) database demonstrate a similarly low rate of ureteral injury in colectomies $(0.6 \%)$, but there was no significant difference in injury rate between laparoscopic and open cases. ${ }^{9}$

A retrospective European population-based study of colon and rectal surgery found a ureteral injury rate of $0.44 \%$, with a higher incidence in laparoscopic surgery on multivariate analysis (OR: 1.64). Multivariate analysis for the subset of rectal cancer patients demonstrated a higher rate of ureteral injury in the laparoscopic group compared with open (OR: 2.67, $p=0.01)^{10}$

Iatrogenic ureteral injury may lead to significant morbidities depending on the severity of injury, including urinary tract infection, urinoma, fistula, and renal failure. ${ }^{11} \mathrm{~A}$ recognized ureteral injury will undoubtedly prolong the operative time, and a missed injury is likely to warrant further procedures, if not a major operation. ${ }^{12}$

\section{Techniques for Injury Prevention}

Knowledge of the anatomy and careful dissection are the most important steps to avoid ureteral injury. Visualization of the ureter prior to the transection of the mesocolon and mesenteric vessels is crucial to preventing ureteral injury. The ureter can be seen through the parietal peritoneum and identified by its vermiculating activity, which can be elicited by applying gentle pressure to the ureter. ${ }^{1}$ Staying in the proper plane of dissection will help in the avoidance of ureteral injury. When mobilizing the colon along the white line of Toldt, maintaining the dissection plane just on the colonic side of the white line will ensure the lateralization of the retroperitoneal structures such as the ureter and the gonadal vessels. For the medial to lateral approach of laparoscopically mobilizing the mesentery off the retroperitoneum, one must first locate the sacral promontory, identify the pathway of the inferior mesenteric and superior hemorrhoidal artery, and initiate the plane of dissection just below the mesenteric vessels. This will help ensure access to the correct plane. Finding the appropriate planes can be difficult in patients with significant inflammation or prior pelvic surgery. In these cases, ureteral stents can be helpful in the identification of the ureters and assist in the immediate recognition of ureteral injuries. ${ }^{13,14}$

Many series have shown that ureteral stents are helpful in the intraoperative recognition of ureteral injury. ${ }^{15,16}$ However, there are no clear indications on when to place a prophylactic ureteral stent prior to colorectal surgery. An NSQIP study found that predictors of ureteral stent placement were diverticular disease (OR: 3.37), LAR (OR: 1.43), APR (OR: 1.39), recent radiotherapy (OR: 1.84), and more recent year of operation (OR: 1.08). There was no difference in renal complications, urinary tract infection, reoperation, sepsis, and 30day mortality in patients who had ureteral stent placement compared with those who did not, but there was a small increase of $5.4 \%$ in length of stay. ${ }^{17}$ The average procedure time is 16 minutes for unilateral stent insertion and 21 minutes for bilateral stent insertion. ${ }^{18} \mathrm{~A}$ case-control study from the Cleveland Clinic evaluated the use and the morbidity of ureteral stents in laparoscopic colorectal surgery and demonstrated no difference in ureteral injury, laparoscopic to open conversion rate, duration of catheterization, UTI, and length of stay. ${ }^{19}$

In summary, the placement of ureteral stents may be particularly helpful in operations for inflammatory processes such as severe Crohn disease or diverticulitis. ${ }^{20,21}$ They are commonly thought to reduce the risk of a missed ureteral injury, although this is not a guarantee as a large series found that stents did not ensure intraoperative recognition of the ureteral injury. ${ }^{11}$ Ureteral stents may decrease the risk of conversion from laparoscopy to laparotomy for the reason of failure to identify the ureter. ${ }^{19,22}$

Although rare, potential complications of prophylactic ureteral stent placement include ureteral injury, postoperative urinary tract infection, obstructive oliguria, hematuria, renal failure, and increased operative time..$^{23-25}$

\section{Intraoperative Techniques to Identify Suspected Injuries}

Early recognition and repair of ureteral injury can decrease associated morbidities. Ureteral stent placement prior to the case may aid in early recognition. In cases without preoperative ureteral stent placement in which ureteral injury is suspected, meticulous dissection of the ureter should be 
performed. If it cannot be identified, a ureteral stent can be placed during the operation. If an injury cannot be identified, diagnosis can be confirmed by giving intravenous methylene blue or indigo carmine, performing an on-table IVP, or by givingretrograde injection of radiographic contrast or methylene blue through ureteral catheter.

\section{Strategies to Prevent Injuries}

\section{Inflammation/Reoperative Surgery}

A key principle in preventing ureteral injury in the face of severe inflammatory or adhesive disease is to identify the ureter in an unaffected area. For example, in cases involving a large diverticular phlegmon in the sigmoid colon, colonic mobilization should be initiated at the level of the proximal descending colon so that the kidney and ureter can be identified proximally and traced inferiorly into the diseased area. A medial to lateral approach is another option for identifying the ureter if the lateral dissection is too difficult. In inflammatory conditions such as diverticulitis, the presacral space may offer a clear point of injury and may be entered at the sacral promontory on the right side of the rectum. Reoperative fields may result in significant displacement of the ureter from its normal location.

\section{Obese Patients}

Obesity is another risk factor for ureteral injuries, as the ureters in these patients are often displaced medially by large deposits of retroperitoneal fat, and are also encapsulated in fatty tissue. If the ureter cannot be located in the course of an operation on an obese individual, continuing the dissection medially may help in localizing the ureter.

The colonic or rectal mesentery should never be divided or ligated unless one has clearly identified the ureter. During high ligation of the inferior mesenteric artery, the left ureter must be identified after clamping the vessel before division or before activating a vessel sealing device or a stapler. If one cannot identify the ureter during a minimally invasive procedure, converting to an open approach is advised before proceeding to division of the mesentery and resection.

\section{Management}

If an injury is recognized during the operation, any necessary and feasible repairs should be performed during the operation, taking into account the mechanism, location, extent of injury, surgeon's experience, and availability of a urology consultant.

Minor contusions can by managed with the insertion of a ureteral stent. ${ }^{26}$ For major contusions or compromised blood supply, the injured part of the ureter is debrided back to healthy tissue and an ureteroureterostomy is performed. This requires mobilization of the remaining ureter without compromising the vascular supply. If inadvertent suturing or clamping of the ureter occurs, management consists of removing the suture or clamp, assessing its viability and extent of damage, repairing it primarily, and placing a ureteral stent for 4 to 6 weeks. Imaging studies are performed to assess for subsequent ureteral stricture. ${ }^{1,27-29}$
Energy sources used during surgery can cause ureteral injury due to devascularization. This type of injury usually goes unnoticed and presents in the postoperative period with ureteral stricture or fistula. If it is recognized at the time of the operation, a ureteral stent is placed and imaging is performed 3 months following stent removal to assess for stricture development. ${ }^{1}$

The strategy for repairing a laceration or transection depends on the extent and location of the injury. The principles of ureteral repair include a tension-free spatulated anastomosis over a ureteral stent using absorbable sutures, with the placement of a closed suction drain. ${ }^{1}$ Repair can be performed through open or minimally invasive techniques. ${ }^{30}$ Primary repair in forms of ureteroureterostomy (to either the injured ureter or the contralateral ureter) or ureteroneocystostomy is the preferred approach if the anastomosis can be performed without tension. With extensive ureteral damage that precludes a tension-free primary anastomosis, repair may consist of a flap procedure, autotransplantation, or nephrectomy.

\section{Distal Ureter Injury}

The lower ureter extends from the inferior border of the sacroiliac joint to the ureterovesical junction. ${ }^{1}$ Depending on the severity of the injury and the proximity to the ureterovesical junction, laceration injuries are repaired by primary anastomosis, ureteral implant, or psoas hitch. ${ }^{1}$ If the ureteral injury is 3 to $4 \mathrm{~cm}$ proximal to the ureterovesical junction, ureteroureterostomy is performed by mobilization of the ureter, with debridement of the proximal and distal ureteral segments involved in the injury. This is followed by spatulation of both ureteral ends prior to performing a tension-free anastomosis using absorbable sutures over a stent. The site of repair is drained and the retroperitoneum is closed over the repair. $^{26,27}$

If the injury is within the distal $2 \mathrm{~cm}$ from the ureterovesical junction, repair with ureteroneocystostomy is performed, with either intravesical or extravesical technique. $^{31,32}$

The intravesical technique involves the creation of a submucosal tunnel to work as flap valve to prevent reflux. The ureter is brought into the bladder wall and then tunneled under the mucosa before being brought into the bladder. Anastomosis to the mucosa is performed with interrupted absorbable sutures. ${ }^{33}$ The extravesical technique involves incision of the detrusor muscle to create a trough for the ureter, anastomosis of the ureter to the mucosa, and closure of the trough to create an antirefluxing mechanism. ${ }^{34}$ Mobilization of the bladder on the injured side is often required for both techniques.

If ureteroureterostomy or ureteroneocystostomy cannot be performed without tension, a psoas hitch should be performed. This entails mobilization of the bladder and creating a cystotomy on its anterior wall. The dome of the mobilized bladder is anchored to the psoas tendon with nonabsorbable sutures. The ureter is reimplanted over a stent and the cystotomy closed with absorbable sutures. A closed suction drain is placed over the repair. ${ }^{35,36}$ 


\section{Mid Ureter Injury}

The mid-ureter extends from the upper to the lower border of the sacroiliac joint. For a short segment injury, the optimal repair is ureteroureterostomy. For extensive injuries where a tension-free anastomosis cannot be performed, a psoas hitch or Boari flap with ureteroneocystostomy, or transureteroureterostomy will be needed.

A Boari flap entails complete mobilization of the bladder, and creation of a rectangular flap on the anterior surface of the bladder while preserving the superior vesicle artery. Nonabsorbable sutures are used to suture the flap to the psoas tendon and the ureter is tunneled through the proximal portion of the flap. The flap is tubularized and the ureteroneocystostomy is created over a stent with absorbable sutures. A closed suction drain is placed over the anastomosis and an indwelling bladder catheter is left in for 7 to 14 days. The stent can be removed 4 to 6 weeks after repair. ${ }^{37,38}$

Transureteroureterostomy is an anastomosis between the two ureters in which the injured ureter is tunneled under the mesentery across the midline to the intact contralateral ureter. Both ureters need to be mobilized to allow for tension-free anastomosis and the ureteroureterostomy is performed with absorbable sutures. A closed suction drain needs to be placed. ${ }^{26,39-41}$

\section{Proximal Ureter Injury}

The proximal ureter extends from the ureteropelvic junction to the upper border of sacroiliac joint. Repair of injuries in this location are managed with ureteroureterostomy, autotransplantation, ileal or appendiceal interposition graft, or nephrectomy depending on the severity of the injury. ${ }^{1}$

Ureteroureterostomy is the procedure of choice for proximal ureteral injury if a tension-free anastomosis can be achieved. Extra length can be achieved through inferior mobilization of the kidney that is then fixed to the psoas muscle (nephropexy). ${ }^{1}$ If the injury is extensive and sufficient length cannot be obtained, other repair options should be considered.

Ileal or appendiceal interposition graft should only be considered if other alternatives are not feasible. Both ureteral segments are mobilized, and ureteral-ileal or ureteral-appendiceal anastomosis is performed with absorbable sutures. This procedure is contraindicated in cases of Crohn disease or radiation enteritis. ${ }^{1,42,43}$

Nephrectomy should only be considered in very extensive injuries that are not amenable for other repair options. A normal contralateral kidney must be present prior to performing this procedure. ${ }^{26}$

Autotransplantation is a complex procedure and should only be considered if contralateral kidney is absent or poorly functioning. The ipsilateral kidney is harvested and anastomosed to the iliac artery and vein, and the ureter is anastomosed directly to the bladder. ${ }^{37}$

Missed injuries present in the postoperative period as abdominal or flank pain, fever, intra-abdominal collections, and fistulas, and can be managed in a variety of ways. ${ }^{44}$ The treatment options include ureteral stent placement, percutaneous nephrostomy tube placement, or repair with any of the above techniques, depending on the timing of diagnosis to the index operation and also the severity and nature of the injury. ${ }^{27,45}$

\section{Bladder}

Bladder injuries during colorectal surgery are uncommon, with an incidence of $<1 \%{ }^{5}$ Patients who have had previous pelvic surgery, had chronic inflammation or infection with a phlegmon that is adherent to the bladder, received radiation, or have an extensive tumor with bladder infiltration are at increased risk of bladder injury. Injuries can occur during the dissection of densely adherent rectosigmoid tumors or diverticular disease from the bladder wall or during trocar insertion in MIS. ${ }^{1}$

To avoid bladder injuries and to manage them if they occur, some anatomical considerations must be considered. The superior and posterior portions of the bladder are covered with peritoneum, whereas the ventral and lateral surfaces are extraperitoneal. When the bladder is full, it distends outside of the pelvis, which subjects it to an injury during trocar insertion if it was not drained preoperatively.

Injuries to the bladder, if not recognized intraoperatively, may present later with oliguria, urinary ascites with increased abdominal girth or drain output, drainage from the surgical incision, and ileus. ${ }^{1}$ The diagnosis is confirmed with a computed tomography (CT)cystogram or fluoroscopic cystogram, ${ }^{46,47}$ and the injury is defined as intraperitoneal or extraperitoneal to guide the management. ${ }^{29,48}$

\section{Management}

If recognized intraoperatively, immediate repair of a bladder injury should be performed. The type of repair depends primarily on the location and extent of the injury, which is described by the following grading system ${ }^{49}$ :

Grade 1: contusion, intramural hematoma, or partial thickness laceration

Grade 2: extraperitoneal bladder wall laceration $<2 \mathrm{~cm}$

Grade 3: extraperitoneal $>2 \mathrm{~cm}$ or intraperitoneal $<2$ $\mathrm{cm}$

Grade 4: intraperitoneal bladder wall laceration $>2 \mathrm{~cm}$

Grade 5: intra- or extraperitoneal bladder wall laceration involving the trigone or bladder

For small extraperitoneal injuries, placement of Foley catheter for 7 to 14 days is sufficient treatment. Large extraperitoneal or intraperitoneal injuries involving the ventral bladder, dome, or posterior wall away from the ureteral orifices require surgical repair with a two-layer primary closure of the mucosal and seromuscular layers using absorbable sutures, and an indwelling bladder catheter 7 to 14 days. Prior to removal of the catheter, a cystogram is performed to rule out a leak.

Posterior injuries at the base of the bladder involving the trigone are more difficult to repair due to the proximity of the ureteral orifices and the risk of inadvertent ligation of the ureter during repair. Careful assessment for ureteral injury is required. Repair is performed through anterior mobilization 
of the bladder with anterior cystotomy at the dome, retrograde placement of ureteral catheters through the ureteral orifices, and two-layer closure of the posterior wall through the anterior cystotomy. ${ }^{1,50}$ One or both of the ureters may require reimplantation to the bladder depending on the location and degree of the injury.

Missed injuries can present as urinomas or urine drainage through a rectal stump or vaginal cuff. The diagnosis is confirmed with an abdominopelvic CT or cystogram. ${ }^{47,51}$ Fistulas to the bowel or vagina can be surgically taken down and repaired with placement of an omental flap between the two organs. They can also be managed with urinary or fecal diversion depending on the nature of the fistula. ${ }^{50}$

\section{Urethra}

Urethral injuries during colorectal surgery are also rare. Direct injury may result from surgery for extensive anorectal tumors, during the perineal portion of APR, or extensive debridement for perineal soft tissue infections, and typically involves the membranous or prostatic portion. ${ }^{1}$ The risk of injury is increased with the presence of a locally advanced anterior rectal tumor or with postradiation changes that may distort the anatomical planes.

Intraoperative recognition of the injury often occurs when the bladder catheter is seen through the defect. Suspicion of an injury in the operating room may be confirmed with a retrograde injection of methylene blue into the urethral meatus. Missed urethral injuries can present later with symptoms of rectourethral or urethrocutaneous fistula including pneumaturia, fecaluria, or urine leakage per rectum or perineum, or symptoms of urethral stricture with bladder outlet obstruction. ${ }^{1}$ Cystoscopy, retrograde urethrogram, and an examination under anesthesia may be useful for diagnostic workup. $^{1}$

\section{Management}

If the injury is recognized intraoperatively, a primary tensionfree repair may be performed by mobilizing periurethral tissue depending on the extent of injury. For small defects, primary repair with absorbable sutures is sufficient with an indwelling urinary catheter for 2 to 4 weeks. Placement of omental or local tissue flaps is recommended if patient had received neoadjuvant radiation therapy to decrease the risk of fistula formation. Tissue flaps are also useful in urethral reconstruction in cases of extensive urethral loss. For extensive injuries where primary repair is not feasible, a suprapubic catheter is placed with delayed repair after few months. ${ }^{1}$

Management of missed urethral injuries and resultant fistulas depends on fistula location and history of radiation. General principles for repair include urinary drainage with fistula takedown and interposition of a local tissue flap between the two lumens. ${ }^{52}$

Complex rectourethral fistulas may require fecal diversion prior to definitive repair. Definitive repair for large fistulas with previous radiation will require complex repair with a buccal graft and/or myocutaneousflap. ${ }^{53-55}$ Other cases may not be amenable to surgical repair and will need at least permanent urinary and fecal diversion if not completion proctectomy.

\section{Other Genitourinary Complications}

During pelvic dissection in colorectal surgery, genital organs are at risk of injury, which might result in urinary and sexual dysfunction. Women are also at risk for infertility after pelvic surgery.

\section{Urinary Dysfunction}

Following APR or LAR, 30 to $60 \%$ of the patients may experience urinary dysfunction manifesting as retention or incomplete emptying. ${ }^{56}$ This dysfunction is attributable to anatomical changes within the pelvis or autonomic nerve injury leading to an impairment of the parasympathetic innervation to the detrusor muscle or the sympathetic innervation to the bladder neck, trigone, and urethra. Patients undergoing radical resection of rectal cancer are at increased risk of urinary dysfunction with APR compared with LAR, tumor location $\leq 5 \mathrm{~cm}$ from the anal verge, history of radiation therapy, and intra-abdominal sepsis. ${ }^{57}$

Most cases of postoperative urinary retention are shortlived. Persistent urinary dysfunction warrants workup with urodynamic studies to assess the bladder capacity, the sensation to void, and the residual urinary volume. ${ }^{58}$

The technique of total mesorectal excision with autonomic nerve preservation has demonstrated success in reducing the incidence of postoperative urinary dysfunction. ${ }^{59,60}$ Studies comparing minimally invasive versus open colorectal surgery have not found differences in the outcome of urinary dysfunction. ${ }^{61-63}$

\section{Sexual Dysfunction}

Autonomic nerve injury during colorectal surgery can also result in sexual dysfunction. These injuries occur more during pelvic dissection for cancer and IBD in the course of APR and LAR. Sympathetic nerves injury can occur during high ligation of the inferior mesenteric artery or during the posterior dissection at the level of the sacral promontory and will result in retrograde ejaculation. Injury to the parasympathetic nerves can occur during the lateral and anterior pelvic dissection and will result in erectile dysfunction.

While some surgeons advocate a close rectal dissection in proctectomies for benign indications such as IBD to minimize these complications, no difference has been noted in rates of sexual dysfunction compared with standard total mesorectal excision (TME) techniques. ${ }^{64}$

While patients with IBD may actually experience improved sexual function after restorative proctocolectomy, ${ }^{65}$ patients undergoing radical rectal cancer resections are found to have significant rates of dyspareunia and more infrequent sexual activity, especially those who undergo APR. ${ }^{57}$ While laparoscopic versus open rectal cancer resections are comparable with regard to postoperative sexual dysfunction, there are worse outcomes in patients who underwent TME or an 
operation that was converted from laparoscopic approach to open. $^{61}$

\section{Female Infertility}

Following restorative proctocolectomy, 26 to $48 \%$ of women are at risk for infertility. ${ }^{65-68}$ Infertility is attributed to pelvic adhesions that prevent normal passage of eggs into the fallopian tubes. This significant risk should be discussed preoperatively, as women may wish to delay pelvic surgery until she is done bearing children. It is unclear whether MIS reduces this risk. ${ }^{69}$

\section{Summary}

Injury to genitourinary organs during colorectal surgery is uncommon, although the risk increases with operative complexity. Prevention of such injuries with meticulous efforts to delineate the anatomy is crucial. In the event of an injury, skilled urologic expertise should be obtained to decrease the potential morbidity. Unrecognized injuries can result in devastating sequelae, sometimes requiring multiple procedures for repair.

\section{References}

1 Delacroix SE Jr, Winters JC. Urinary tract injures: recognition and management. Clin Colon Rectal Surg 2010;23(2):104-112

2 Bothwell WN, Bleicher RJ, Dent TL. Prophylactic ureteral catheterization in colon surgery. A five-year review. Dis Colon Rectum 1994;37(4):330-334

3 Kyzer S, Gordon PH. The prophylactic use of ureteral catheters during colorectal operations. Am Surg 1994;60(3):212-216

4 Selzman AA, Spirnak JP. Iatrogenic ureteral injuries: a 20-year experience in treating 165 injuries. J Urol 1996;155(3):878-881

5 Rose J, Schneider C, Yildirim C, Geers P, Scheidbach H, Köckerling F. Complications in laparoscopic colorectal surgery: results of a multicentretrial. Tech Coloproctol 2004;8(Suppl 1):s25-s28

6 Leff EI, Groff W, Rubin RJ, Eisenstat TE, Salvati EP. Use of ureteral catheters in colonic and rectal surgery. Dis Colon Rectum 1982; 25(5):457-460

7 Cass AS, Bubrick MP. Ureteral injuries in colonic surgery. Urology 1981;18(4):359-364

8 Halabi WJ, Jafari MD, Nguyen VQ et al. Ureteral injuries in colorectal surgery: an analysis of trends, outcomes, and risk factors over a 10-year period in the United States. Dis Colon Rectum 2014;57(2):179-186

9 Zafar SN, Ahaghotu CA, Libuit L, et al. Ureteral injury after laparoscopic versus open colectomy. JSLS 2014;18(3):pii: e2014.00158; doi:10.4293/JSLS.2014.00158

10 Andersen P, Andersen LM, Iversen LH. Iatrogenic ureteral injury in colorectal cancer surgery: a nationwide study comparing laparoscopic and open approaches. SurgEndosc 2015;29(6): 1406-1412

11 Palaniappa NC, Telem DA, Ranasinghe NE, Divino CM. Incidence of iatrogenic ureteral injury after laparoscopic colectomy. Arch Surg 2012;147(3):267-271

12 Dwyer PL. Urinary tract injury: medical negligence or unavoidable complication? IntUrogynecol J 2010;21(8):903-910

13 Pokala N, Delaney CP, Kiran RP, Bast J, Angermeier K, Fazio VW. A randomized controlled trial comparing simultaneous intra-operative vs sequential prophylactic ureteric catheter insertion in reoperative and complicated colorectal surgery. Int J Colorectal Dis 2007;22(6):683-687
14 Burks FN, Santucci RA. Management of iatrogenic ureteral injury. TherAdvUrol 2014;6(3):115-124

15 Al-Awadi K, Kehinde EO, Al-Hunayan A, Al-Khayat A. Iatrogenic ureteric injuries: incidence, aetiological factors and the effect of early management on subsequent outcome. IntUrolNephrol 2005; 37(2):235-241

16 Phipps JH, Hawthorn RJS. Transilluminating ureteral stents for prevention of operative ureteral injury during laparoscopic hysterectomy. GynaecolEndosc 1992;1:219-222

17 Speicher PJ, Goldsmith ZG, Nussbaum DP, Turley RS, Peterson AC, Mantyh CR. Ureteral stenting in laparoscopic colorectal surgery. JSurg Res 2014;190(1):98-103

18 Beraldo S, Neubeck K, Von Friderici E, Steinmüller L. The prophylactic use of a ureteral stent in laparoscopic colorectal surgery. Scand J Surg 2013;102(2):87-89

19 Tsujinaka S, Wexner SD, DaSilva G, et al. Prophylactic ureteric catheters in laparoscopic colorectal surgery. Tech Coloproctol 2008;12(1):45-50

20 Jacobs M, Verdeja JC, Goldstein HS. Minimally invasive colon resection (laparoscopic colectomy). SurgLaparoscEndosc 1991; 1(3): 144-150

21 Nam YS, Wexner SD. Clinical value of prophylactic ureteral stent indwelling during laparoscopic colorectal surgery. J Korean Med Sci 2002;17(5):633-635

22 Hong D, Lewis M, Tabet J, Anvari M. Prospective comparison of laparoscopic versus open resection for benign colorectal disease. SurgLaparoscEndoscPercutan Tech 2002;12(4):238-242

23 da Silva G, Boutros M, Wexner SD. Role of prophylactic ureteric stents in colorectal surgery. Asian J EndoscSurg 2012;5(3): 105-110

24 Senagore AJ, Luchtefeld M. An initial experience with lighted ureteral catheters during laparoscopic colectomy. JLaparoendoscSurg 1994;4(6):399-403

25 Chahin F, Dwivedi AJ, Paramesh A, et al. The implications of lighted ureteral stenting in laparoscopic colectomy. JSLS 2002;6(1):49-52

26 Santucci RA, Doumanian LR. Upper Urinary Tract Obstruction and Trauma. 10th ed., Vol 2, Section IX. Philadelphia, PA: Elsevier; 2007:1169

27 Brandes S, Coburn M, Armenakas N, McAninch J. Diagnosis and management of ureteric injury: an evidence-based analysis. BJU Int 2004;94(3):277-289

28 Liu C, Zhang X, Xue D, Liu Y, Wang P. Endoscopic realignment in the management of complete transected ureter. IntUrolNephrol 2014; 46(2):335-340

29 Summerton DJ, Kitrey ND, Lumen N, Serafetinidis E, Djakovic N; European Association of Urology. EAU guidelines on iatrogenic trauma. EurUrol 2012;62(4):628-639

$30 \mathrm{Wu}$ TP, Sa L, Lee CL. Laparoscopic repair of delayed-onset ureter injury. J Minim Invasive Gynecol 2007;14(2):253-255

31 Shah S, Nath V, Gopalkrishnan G, Pandey AP, Shastri JC. Evaluation of extravesical and Leadbetter-Politanoureteroneocystostomy in renal transplantation. Br J Urol 1988;62(5):412-413

32 Haberal M, Emiroglu R, Karakayali H, et al. A corner-saving ureteral reimplantation technique without stenting. Transplant Proc 2006; 38(2):548-551

33 Bruézière J. Leadbetter-Politano operation in the treatment of vesico-ureteral reflux in children. Indications, technic and outcome [in French]. Ann Chir Infant 1966;7(1):67-76

34 Mellin P, Eickenberg HU. Ureteral reimplantation: Lich-Grégoire method. Urology 1978;11(3):315

35 Mathews R, Marshall FF. Versatility of the adult psoas hitch ureteral reimplantation. J Urol 1997;158(6):2078-2082

36 Ahn M, Loughlin KR. Psoas hitch ureteral reimplantation in adults -analysis of a modified technique and timing of repair. Urology 2001;58(2):184-187

37 Benson MC, Ring KS, Olsson CA. Ureteral reconstruction and bypass: experience with ileal interposition, the Boari flap-psoas hitch and renal autotransplantation. J Urol 1990;143(1):20-23 
38 Simmons MN, Gill IS, Fergany AF, Kaouk JH, Desai MM. Technical modifications to laparoscopic Boari flap. Urology 2007;69(1): $175-180$

39 Smith IB, Smith JC. Trans-uretero-ureterostomy: British experience. Br J Urol 1975;47(5):519-523

40 Ehrlich RM, Skinner DG. Complications of transureteroureterostomy. J Urol 1975;113(4):467-473

41 Sandoz IL, Paull DP, MacFarlane CA. Complications with transureteroureterostomy. J Urol 1977;117(1):39-42

42 Armatys SA, Mellon MJ, Beck SD, Koch MO, Foster RS, Bihrle R. Use of ileum as ureteral replacement in urological reconstruction. J Urol 2009;181(1):177-181

43 Wolff B, Chartier-Kastler E, Mozer P, Haertig A, Bitker MO, Rouprêt M. Long-term functional outcomes after ileal ureter substitution: a single-center experience. Urology 2011;78(3):692-695

44 Hewett PJ, Joseph M, Bokey EL. Ureteric ischaemia following major colorectal resection. Aust N Z J Surg 1995;65(2):137-139

45 McAninchJack W. Smith's General Urology. 17th ed. New York: McGraw Hill; 2008:201-209

46 Deck AJ, Shaves S, Talner L, Porter JR. Computerized tomography cystography for the diagnosis of traumatic bladder rupture. J Urol 2000;164(1):43-46

47 Jarrett TW, Vaughan ED Jr. Accuracy of computerized tomography in the diagnosis of colovesical fistula secondary to diverticular disease. J Urol 1995;153(1):44-46

48 Vaccaro JP, Brody JM. CT cystography in the evaluation of major bladder trauma. Radiographics 2000;20(5):1373-1381

49 van Goor H. Consequences and complications of peritoneal adhesions. Colorectal Dis 2007;9(2, Suppl 2):25-34

50 Alperin M, Mantia-Smaldone G, Sagan ER. Conservative management of postoperatively diagnosed cystotomy. Urology 2009; 73(5):1163.e17-1163.e19

51 Patel BN, Gayer G. Imaging of iatrogenic complications of the urinary tract: kidneys, ureters, and bladder. RadiolClin North Am 2014;52(5):1101-1116

52 Fengler SA, Abcarian $\mathrm{H}$. The York Mason approach to repair of iatrogenic rectourinaryfistulae. Am J Surg 1997;173(3):213-217

53 Bruce RG, El-Galley RE, Galloway NT. Use of rectus abdominis muscle flap for the treatment of complex and refractory urethrovaginalfistulas. J Urol 2000;163(4):1212-1215

54 Zmora O, Tulchinsky H, Gur E, Goldman G, Klausner JM, Rabau M. Gracilis muscle transposition for fistulas between the rectum and urethra or vagina. Dis Colon Rectum 2006;49(9):1316-1321

55 Elliott SP, McAninch JW, Chi T, Doyle SM, Master VA. Management of severe urethral complications of prostate cancer therapy. J Urol 2006;176(6, Pt 1):2508-2513

56 Banerjee AK. Sexual dysfunction after surgery for rectal cancer. Lancet 1999;353(9168):1900-1902
57 Tekkis PP, Cornish JA, Remzi FH, et al. Measuring sexual and urinary outcomes in women after rectal cancer excision. Dis Colon Rectum 2009;52(1):46-54

58 Chang PL, Fan HA. Urodynamic studies before and/or after abdominoperineal resection of the rectum for carcinoma. J Urol 1983;130(5):948-951

59 Pocard M, Zinzindohoue F, Haab F, Caplin S, Parc R, Tiret E. A prospective study of sexual and urinary function before and after total mesorectal excision with autonomic nerve preservation for rectal cancer. Surgery 2002;131(4):368-372

60 Maas CP, Moriya Y, Steup WH, Klein Kranenbarg E, van de Velde CJ. A prospective study on radical and nerve-preserving surgery for rectal cancer in the Netherlands. Eur J SurgOncol 2000;26(8): 751-757

61 Jayne DG, Brown JM, Thorpe H, Walker J, Quirke P, Guillou PJ. Bladder and sexual function following resection for rectal cancer in a randomized clinical trial of laparoscopic versus open technique. Br J Surg 2005;92(9):1124-1132

62 Andersson J, Abis G, Gellerstedt M, et al. Patient-reported genitourinary dysfunction after laparoscopic and open rectal cancer surgery in a randomized trial (COLOR II). Br J Surg 2014;101(10): 1272-1279

63 Luca F, Valvo M, Ghezzi TL, et al. Impact of robotic surgery on sexual and urinary functions after fully robotic nerve-sparing total mesorectal excision for rectal cancer. Ann Surg 2013;257(4): 672-678

64 Lindsey I, George BD, Kettlewell MG, Mortensen NJ. Impotence after mesorectal and close rectal dissection for inflammatory bowel disease. Dis Colon Rectum 2001;44(6): 831-835

65 Cornish JA, Tan E, Teare J, et al. The effect of restorative proctocolectomy on sexual function, urinary function, fertility, pregnancy and delivery: a systematic review. Dis Colon Rectum 2007; 50(8):1128-1138

66 Waljee A, Waljee J, Morris AM, Higgins PD. Threefold increased risk of infertility: a meta-analysis of infertility after ileal pouch anal anastomosis in ulcerative colitis. Gut 2006;55(11): $1575-1580$

67 Olsen KO, Joelsson M, Laurberg S, Oresland T. Fertility after ileal pouch-anal anastomosis in women with ulcerative colitis. Br J Surg 1999;86(4):493-495

68 ØrdingOlsen K, Juul S, Berndtsson I, Oresland T, Laurberg S. Ulcerative colitis: female fecundity before diagnosis, during disease, and after surgery compared with a population sample. Gastroenterology 2002;122(1):15-19

69 Hull TL, Joyce MR, Geisler DP, Coffey JC. Adhesions after laparoscopic and open ileal pouch-anal anastomosis surgery for ulcerative colitis. Br J Surg 2012;99(2):270-275 